Article

\title{
Evaluating the Reduction of Stress Intensity Factor in Center-Cracked Plates Using Piezoelectric Actuators
}

\author{
Ahmed Abuzaid ${ }^{1}$, Meftah Hrairi ${ }^{2, *(1)}$ and Mohd Sultan Ibrahim Bin Shaik Dawood ${ }^{2}$ \\ 1 Department of Aeronautical Engineering, Sudan University of Science and Technology, Street 61, \\ Khartoum 11111, Sudan; ahmezaid@gmail.com \\ 2 Department of Mechanical Engineering, International Islamic University Malaysia, P.O. Box 10, \\ 50728 Kuala Lumpur, Malaysia; sultan@iium.edu.my \\ * Correspondence: meftah@iium.edu.my; Tel.: +603-6196-4581
}

Received: 22 February 2018; Accepted: 25 May 2018; Published: 27 May 2018

\begin{abstract}
Active repairs using smart materials such as piezoelectric actuators can play a significant role in reducing the crack damage propagation in engineering structures. This study analytically and numerically investigated the active repair of center-cracked plates using piezoelectric actuators. First, the stress intensity factor (SIF) for a center-cracked plate due to stress produced by a piezoelectric actuator is analytically modeled. This analytical model is obtained by applying the method of weight functions. In the second step, the solution is found for the center-cracked plate due to external loading from known linear elastic fracture mechanics. These solutions are then superimposed, taking into account the superposition principle to yield the total stress intensity factor for the integrated piezoelectric actuator to the center-cracked plate. Finally, the proposed theoretical model is verified by finite element simulation. The results indicated that the relative errors of the analytical model and the FEA results are less than $5 \%$ in all the cases studied in this paper.
\end{abstract}

Keywords: piezoelectric actuator; fracture mechanics; active repair; stress intensity factor

\section{Introduction}

In the repair of structure cracks, the main objective is to decrease the singularity of the stress at the crack tip. Traditionally, the use of bonded composite repair is considered an efficient and economic method. In this type of repair, composite patches are bonded to the host structure to increase the service life of the structural crack.

Recently, researchers have conducted considerable work to study active repair and control of cracked structures using piezoelectric actuators [1,2]. In the active repair of cracks, the main objective is to decrease the singular stress at the vicinity of the crack tip. The basic idea in their research is to induce stress with the piezoelectric actuator in the singular area at the crack tip in order to counteract the external load. Several methodologies have been developed to study the active repair of the cracked structure [3-14]. Due to their electromechanical coupling effects, piezoelectric materials are commonly used as sensors or actuators in various engineering structures. The piezoelectric actuator's response to a change of the electric field or to the deformation of the structure compared to the shape memory is incredibly quick [1], which allows for the piezoelectric actuator to be adjusted instantly when the external environment is altered. However, the application of piezoelectric actuators is still challenging, since a considerably high driving voltage is needed to attain practical forces or displacements, and thus the real-world application of the actuators is still limited [15]. Traditional piezoelectric drive methods use an AC voltage source that causes the piezoelectric layer to expand and contract by the converse piezoelectric effect. Depending on the application, the required driving electrical AC voltage for these actuators is typically in the range of $100 \mathrm{~V}$ to $1000 \mathrm{~V}$, quite far from the 9 to $24 \mathrm{~V}$ of common 
batteries. Thus, different necessary step-up conversion to drive the piezoelectric actuator had been proposed in the literature. Vazquez Carazo and Uchino [16] and Vazquez Carazo [17] proposed a novel DC-AC converter using a piezoelectric transformer, capable of converting a $24 \mathrm{~V}$ DC input voltage up to $600 \mathrm{~V}$ AC output voltage with frequency and magnitude control for driving piezoelectric actuators. Other circuit topologies with higher step-up ratios and better control strategies to drive piezoelectric actuators were also presented [18], but these topologies often mean larger volume and more complex control methods. So, micro converters are still being investigated to boost the low voltage energy source. $\mathrm{Xu}$ et al. [19] designed and implemented a micro converter that operates in $\mathrm{DC} / \mathrm{DC}$ or DC/AC stages for driving a piezoelectric actuator. In the DC/DC stage, a DC voltage of up to $100 \mathrm{~V}$ was obtained from a $3.7 \mathrm{~V}$ lithium battery, whereas it can also produce $100 \mathrm{~V}, 80 \mathrm{~Hz} \mathrm{AC}$ in the DC/AC stage.

It is well-known that elastic linear fracture mechanics give accurate results and can describe the stress and strain behaviors at the crack tip. However, the literature reveals that little research has been conducted using the elastic linear fracture mechanics concept. Among the authors having used the fracture mechanics method, Liu [14,20] applied fracture mechanics to study the active repair of cracked beams dominated by Mode I opening displacement. Platz et al. conducted statistical experiments and finite element investigations for crack propagation in bending loads [13]. An approximate analytical derivation for Mode I, restricted to the application of a square actuator and without accounting for the singularity of the stress at the crack tip, was carried out [21]. An investigation to study the influence of adhesive properties on active repair under Mode-I fracture [22] showed that a higher adhesive shear modulus is desired for repairing cracks, as it allows the transfer of the stress induced by the piezoelectric actuator to the host structure. Recently, Abuzaid et al. [23] studied mode I active repair using a piezoelectric actuator. The authors developed an analytical closed-form solution using the virtual crack closure technique, coupling effects of the piezoelectric patch, and singular stress at the crack tip of a center cracked plate. Fesharaki and Golabi [24] investigated the effect of piezoelectric patches and plate stiffness on placement and power of piezoelectric actuators for reduction of the stress concentration factor around a hole in a plate under tension. In a subsequent paper, Fesharaki and Golabi [25] furthered the state of knowledge by specifying the actuators pattern recognition for the optimization of the stress concentration reduction. Maleki and Mohammadi [26] analytically investigated the stability analysis of cracked functionally graded material columns under the effect of piezoelectric patches.

The aim of this research is to study the behavior of a center-cracked plate with an integrated piezoelectric actuator in pure Mode I due to tension stress. First, the stress intensity factor (SIF) for the center-cracked plate due only to the piezoelectric actuation is analytically modeled. Compared to the previous work [23] which was based on the energy release rate to derive the analytical SIF for the center crack plate, the current work uses the weight functions approach to derive the analytical SIF for the center crack plate. In the second step, the solution is found for the center-cracked plate due to external loading from known linear elastic fracture mechanics. These solutions are then superimposed, taking into account the superposition principle, to yield the total stress intensity factor for the integrated piezoelectric actuator to the center-cracked plate. Then, the proposed theoretical model is verified by finite element simulation.

\section{Materials and Methods}

\subsection{Modelling of the Active Repair of the Center-Cracked Plate with Integrated Piezoelectric Actuator}

Figure 1 shows the center-cracked plate subjected to external uniform loading and stresses produced by the piezoelectric actuators. Four piezoelectric patches, bonded face to face from both sides of the hosting plate thickness, were considered (Figure 2). With the assumption that the two loads are perpendicular to the crack surfaces, Mode I is achieved. The goal of this study is to repair the 
crack by imposing opposite stress with the piezoelectric actuator onto the crack surface to counteract the external load.

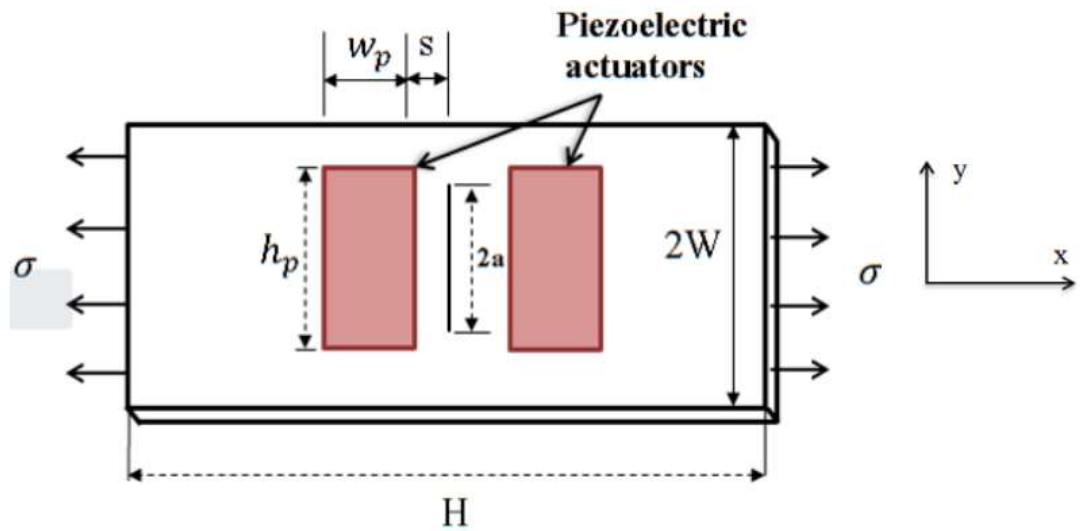

Figure 1. Centre-cracked plate with integrated piezoelectric actuators.

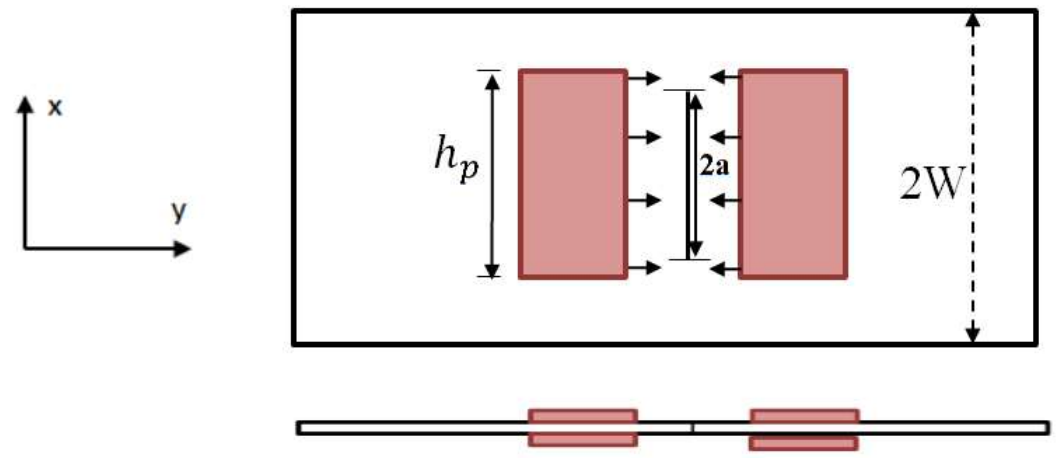

Figure 2. Centre-cracked plate with only piezoelectric actuators active.

From Figure 1, one can see the stress intensity factor for the integrated structure as two sets of problems. One is the stress intensity factor due to external loading and the other is the stress intensity factor due to the piezoelectric actuator. The superposition principle is adopted which indicates that each problem can be treated separately and then the two solutions are superimposed to find the stress intensity factor for the integrated structure, $\mathrm{K}_{\mathrm{I}(\text { total })}$.

The problem of the stress intensity factor $K_{I}$ due to the external loading is well known in the literature [27]. The problem of the stress intensity factor $\mathrm{K}_{\mathrm{I}(\mathrm{p})}$ due to the piezoelectric actuator stress (Figure 2) can be formulated using the weight function approach.

The procedure for determining the weight function as proposed by Bückner [28], allows one to simply determine the stress intensity factors. The stress intensity factor in the event that the weights function is known for a cracked structure can be obtained by multiplying the known weight function by the stress distribution and integrating it along the crack length. The weight function does not depend on the unique stress distribution, but rather just on the geometry of the structure.

Consider a through-thickness crack of length $2 \mathrm{a}$ in a plate and $\sigma_{\mathrm{P}}(\mathrm{x})$ is the distributed stress produced by the piezoelectric actuators along the prospective crack line of a center-crack. To eliminate the effects of the distributed load on the stress intensity factor distribution on the crack surfaces, the plate is assumed to be infinite. The crack length is assumed to be smaller than the piezoelectric actuator width $\left(\mathrm{a}=0.5 \mathrm{~h}_{\mathrm{p}}\right)$ which means that the stresses produced by the patch act on the crack tip singular area. The tip of the crack is in the width $(2 \mathrm{~W})$ direction. In this case, the stress intensity factors are given by [29]:

$$
\mathrm{K}_{\mathrm{I}(\text { piezo })}=\int_{\Gamma_{\mathrm{c}}} \sigma_{\text {Piezo }} \mathrm{h}(\mathrm{x}, \mathrm{a}) \mathrm{dx},
$$


where $h(x, a)$ is the weight function and where $\Gamma$ is the perimeter of the body, and it can be expressed as [28]:

$$
\mathrm{h}(\mathrm{xi}, \mathrm{a})=\frac{\hat{\mathrm{E}}}{2 \mathrm{~K}_{\mathrm{I}}} \frac{\mathrm{du} \mathrm{u}_{\mathrm{y}}}{\mathrm{da}},
$$

where $x i$ represents the $x$ and $y$ coordinate axes defined in Figure 1. Equation (1) allows the determination of the weight function from the opening displacement of the crack for any arbitrary loading. The representation of the $\mathrm{K}_{\mathrm{I}}$ for this configuration is already known when a uniform tensile stress is applied:

$$
\mathrm{K}_{\mathrm{I}}=\sigma \sqrt{\pi \mathrm{a}},
$$

Using Rice [30] and Bueckner [28], $\mathrm{K}_{\mathrm{I}(\mathrm{p})}$ and $\mathrm{K}_{\mathrm{I}}$ can be related as follows:

$$
\mathrm{K}_{\mathrm{I}(\mathrm{p})}=\frac{\hat{\mathrm{E}}}{2 \mathrm{~K}_{\mathrm{I}}}\left[\int_{\Gamma} \mathrm{T}_{\mathrm{i}} \frac{\mathrm{du} \mathrm{u}_{\mathrm{y}}}{\mathrm{da}} \mathrm{d} \Gamma+\int_{\Gamma} \mathrm{F}_{\mathrm{i}} \frac{\mathrm{du} \mathrm{u}_{\mathrm{y}}}{\mathrm{da}} \mathrm{dA}\right],
$$

where $\mathrm{u}_{\mathrm{y}}$ is the displacement in the $\mathrm{y}$-direction and $\mathrm{A}$ is the crack body area. As a consequence of the Westergaard stress function, the crack opening displacement can be expressed as follows [31]:

$$
\mathrm{u}_{\mathrm{y}}=\frac{2 \sigma(\mathrm{x})}{\hat{\mathrm{E}}} \sqrt{\mathrm{x}(2 \mathrm{a}-\mathrm{x})}
$$

where $\hat{E}=E /\left(1-v^{2}\right)$ for plane strain and $E=E$ for plane stress. Differentiate $u_{y}$ with respect to $2 a$ rather than a (since the crack length is $2 \mathrm{a}$ ):

$$
\frac{d u_{y}}{d(2 a)}= \pm \frac{2 \sigma(x)}{E} \sqrt{\frac{x}{2 a-x}}
$$

by inserting Equations (3) and (6) in Equation (2), we obtain the weight function for this crack geometry expressed as

$$
\mathrm{h}(\mathrm{xi}, \mathrm{a})= \pm \frac{1}{\sqrt{\pi \mathrm{a}}} \sqrt{\frac{\mathrm{x}}{2 \mathrm{a}-\mathrm{x}}}
$$

for the active piezoelectric actuator, inserting Equations (5) and (6) in Equation (1) one can determine Mode I stress intensity factor for the two crack tips as follows:

$$
\begin{gathered}
\mathrm{K}_{\mathrm{I}(\mathrm{P})[\mathrm{x}=2 \mathrm{a}]}=\frac{1}{\sqrt{\pi \mathrm{a}}} \int_{0}^{2 \mathrm{a}} \sigma_{\mathrm{P}}(\mathrm{x}) \sqrt{\frac{\mathrm{x}}{2 \mathrm{a}-\mathrm{x}}}, \\
\mathrm{K}_{\mathrm{I}(\mathrm{P})[\mathrm{x}=0]}=\frac{1}{\sqrt{\pi \mathrm{a}}} \int_{0}^{2 \mathrm{a}} \sigma_{\mathrm{P}}(\mathrm{x}) \sqrt{\frac{2 \mathrm{a}-\mathrm{x}}{\mathrm{x}}},
\end{gathered}
$$

in the case of the linear piezoelectric constitutive polarized in the $\mathrm{z}$ direction and perfect bonding between the actuator and the host plate, the force produced by actuator can be expressed as [32]:

$$
F_{p}=\frac{E t T}{\left(E t / E_{p} t_{p}\right)+\alpha} \frac{d_{31}}{t_{p}} V
$$

where $\mathrm{V}$ is the input voltage, $\mathrm{E}$ is the Young's modulus of the host plate, $\mathrm{E}_{\mathrm{p}}$ is the actuator's Young's modulus, $T$ is the width of distributed electrodes, $t_{p}$ is the actuator thickness, $d_{31}$ is the piezoelectric coefficient, and $\alpha$ is a coefficient that depends on the actuator operation mode. Inserting the stress $\sigma_{P}$ into Equations (8) and (9) yields the solution for $\mathrm{K}_{\mathrm{I}(\mathrm{P})}$ due to the piezoelectric actuator.

It should be noted that Equations (8) and (9) show the basic solutions for an infinite center-cracked plate. However, approximations of the dimensionless function $\mathrm{F}(\mathrm{a} / \mathrm{w})$ to account for the geometry 
effects on the cracked body should be considered. Applying the well-known dimensionless function proposed by [27], one can finally obtain

$$
\begin{aligned}
& \mathrm{K}_{\mathrm{I}(\mathrm{p})[\mathrm{x}=2 \mathrm{a}]}=\frac{1}{\sqrt{\pi \mathrm{a}}} \int_{0}^{2 \mathrm{a}} \sigma_{\mathrm{P}}(\mathrm{x}) \sqrt{\frac{\mathrm{x}}{2 \mathrm{a}-\mathrm{x}}} \sqrt{\operatorname{Sec}(\pi \beta / 2)}, \\
& \mathrm{K}_{\mathrm{I}(\mathrm{p})[\mathrm{x}=0]}=\frac{1}{\sqrt{\pi \mathrm{a}}} \int_{0}^{2 \mathrm{a}} \sigma_{\mathrm{P}}(\mathrm{x}) \sqrt{\frac{2 \mathrm{a}-\mathrm{x}}{\mathrm{x}}} \sqrt{\operatorname{Sec}(\pi \beta / 2)},
\end{aligned}
$$

where $\beta=2 \mathrm{a} / \mathrm{w}$.

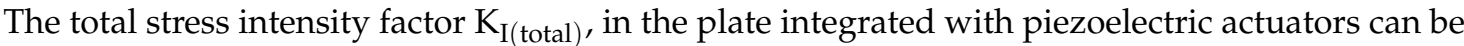
considered using the superposition principle as mentioned earlier as the sum of the stress intensity factor due to external uniform loading $\mathrm{K}_{\mathrm{I}}$ and the stress intensity factor due to the piezoelectric actuator's stresses $\mathrm{K}_{\mathrm{I}(\mathrm{P})}$

$$
\mathrm{K}_{\mathrm{I}(\text { total })}=\mathrm{K}_{\mathrm{I}}+\mathrm{K}_{\mathrm{I}(\mathrm{p})}
$$

Equation (13) represents the general relation for Mode I between the total stress intensity factor $\mathrm{K}_{\mathrm{I}(\text { total })}$, piezoelectric actuator stress intensity factor $\mathrm{K}_{\mathrm{I}(\mathrm{P})}$, and the stress intensity factor due to the external uniform loading $\mathrm{K}_{\mathrm{I}}$. Equation (13) shows that applying the piezoelectric actuator stress $\mathrm{K}_{\mathrm{I}(\mathrm{P})}$ in the opposite direction to counteract the external stress $\mathrm{K}_{\mathrm{I}}$ (by producing compression on the crack surfaces) will help in mitigation of the $\mathrm{K}_{\mathrm{I} \text { (total) }}$. The stress intensity factor $\mathrm{K}_{\mathrm{I}}$ is obtained for the cracked medium under tension loading by using the solution from the known linear fracture problem [27]. The intention of this paper is to actively repair the structure by decreasing the $\mathrm{K}_{\mathrm{I}(\text { total }) \text {, and hence }}$ application of the piezoelectric actuator is chosen to counteract the external stress.

\subsection{Geometrical and Finite Element Models}

The dimensions of the integrated structure considered in this study are shown in Figure 1. The rectangular plate has dimensions of $\mathrm{W}=40 \mathrm{~mm}, \mathrm{H}=200 \mathrm{~mm}$, and thickness of $1 \mathrm{~mm}$. The plate has a crack of length $\mathrm{a}=10 \mathrm{~mm}$ and is subjected to external loading of $1 \mathrm{Mpa}$. The actuator has dimension of $h_{P}=0.2 \mathrm{H}, \mathrm{W}_{\mathrm{p}}=0.1 \mathrm{H}$, and thickness of $0.5 \mathrm{~mm}$. The placement of the piezoelectric actuator is at $1 \mathrm{~mm}$ from the crack tip. The elastic modulus and Poisson's ratios of the host plate are $68.95 \mathrm{GPa}$ and 0.345 , respectively. The piezoelectric actuator properties are showed in Table 1.

Table 1. Materials properties of the piezoelectric patch.

\begin{tabular}{ccccccc}
\hline Parameters & $\mathrm{S}_{\mathbf{1 1}} \mathrm{m}^{2} / \mathbf{N}$ & $\mathrm{S}_{\mathbf{3 3}} \mathrm{m}^{\mathbf{2}} / \mathbf{N}$ & ${ }_{11}^{T}$ & ${ }_{33}^{T}$ & $\mathrm{~d}_{\mathbf{3 1}} \mathrm{m} / \mathbf{V}$ & $\mathrm{d}_{\mathbf{3 2}} \mathrm{m} / \mathbf{V}$ \\
\hline & $19.0 \times 10^{-12}$ & $15.0 \times 10^{-12}$ & 1977 & 2395 & $-2.10 \times 10^{-10}$ & $-2.10 \times 10^{-10}$ \\
\hline
\end{tabular}

The finite element method (FEM) was employed using a commercial finite element code ANSYS 14.5. Coupled element SOLID226 was used for modelling of the piezoelectric actuator. This element is recommended by ANSYS. For the plate quadratic elements SOLID186 (singular element) was employed. Due to symmetry, only one half of the repaired plate was considered. The mesh generated in the region of the crack front was a very fine mesh in order to accurately compute the stress intensity factor.

A typical mesh of the plate with integrated piezoelectric actuator and mesh refinement in the crack tip region is shown in Figure 3. The stress intensity factor is calculated using the interaction integral. This method used the concepts of virtual crack extension and yielded accurate results with fewer mesh requirements. The parametric studies for different geometrical and electrical boundary conditions are conducted by ANSYS parametric design language (APDL). 


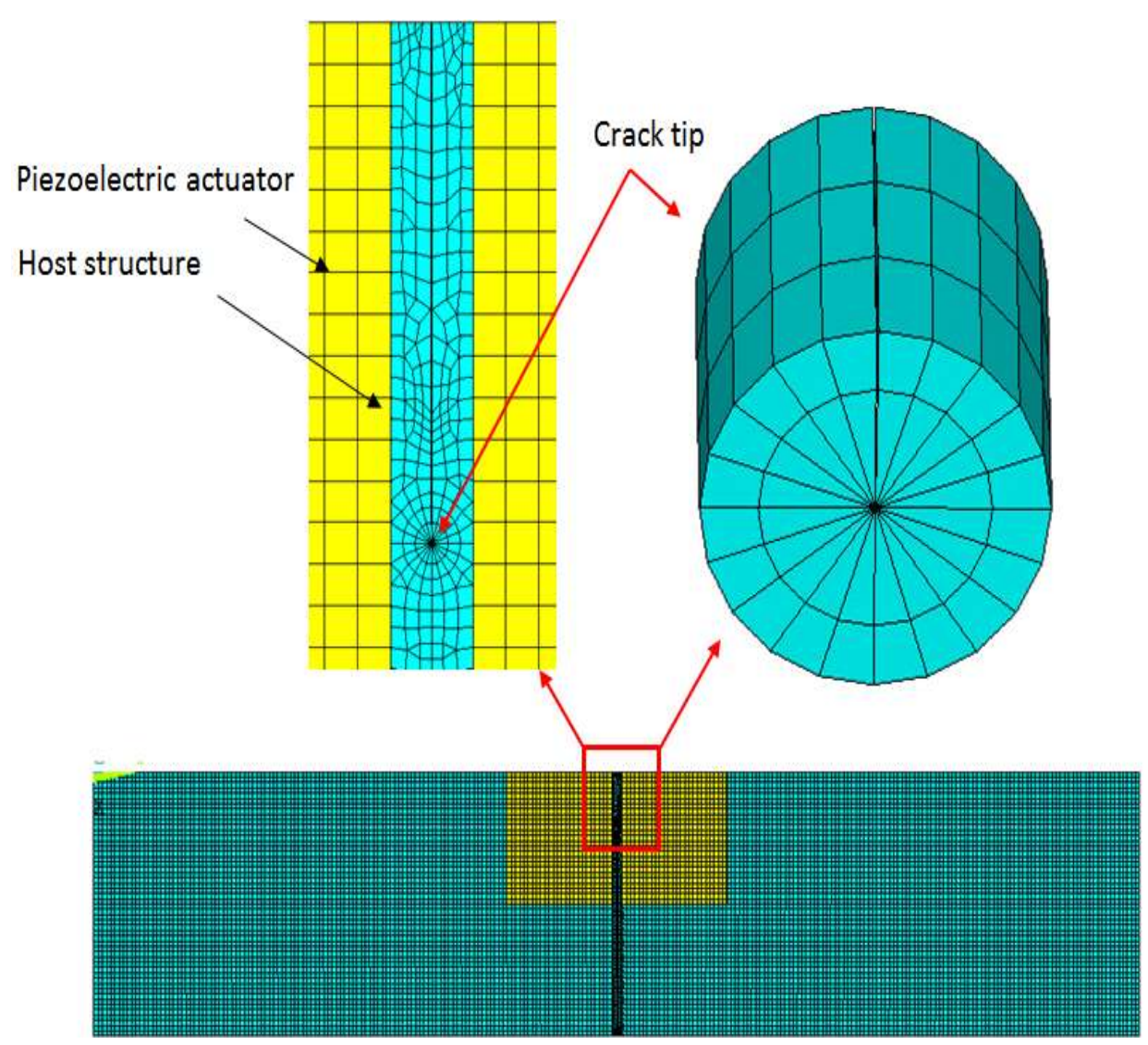

Figure 3. Typical FEM mesh of the repaired plate integrated with piezoelectric actuator and near the crack tip singular element.

The finite element model was validated with the theoretical results through two phases: validation of SIF in cracked plate without piezoelectric patch and validation of the displacement of the piezoelectric actuator operating in extension mode with a certain electric voltage [23]. Furthermore, making specimens with center crack has its own certain limitation, i.e., creating centered cracks in metals. Therefore, the experimental investigation will be considered in future work.

\section{Results and Discussion}

In this section, the obtained results from the proposed model are verified by the finite element analyses. In addition, parametric studies were conducted for different geometries in order to investigate the efficiency of the piezoelectric actuator in the active repair. Table 2 shows the comparison between the normalized stress intensity factors (NSIF) for unpatched and patched cracked plates with applications of $100 \mathrm{~V}$. It is important to mention that the stress intensity factor is normalized by $\sigma_{\text {ext }} \sqrt{\mathrm{a} \pi}$ for the purpose of comparison. For the purpose of conveniently observing the normalized stress intensity factors, the analytical and finite element results listed in Table 2 are shown in Figure 4.

An accurate result with less than 1.2\% discrepancy can be obtained in the case where the piezoelectric actuator width is double the crack length. As mentioned earlier in the assumptions, the stress produced by the actuator must cover the singular stress at the crack tip. However, beyond this length restriction, the proposed analytical model still gives reasonable accuracy.

Figure 4 illustrates that applying the stress produced by the piezoelectric actuator at the crack tip decreased the stress intensity factor. In fact, the compression stress generated by the piezoelectric actuator counteracted the external loading and resulted in SIF mitigations. 
Table 2. Comparison of the NSIFs between unpatched and patched cracks with application of $100 \mathrm{~V}$.

\begin{tabular}{ccccc}
\hline Crack Length $(\mathbf{m m})$ & Theoretical NSIF (without Patch) & Finite Element NSIF & Analytical NSIF & Relative Error (\%) \\
\hline 0.0050 & 1.0083 & 0.4537 & 0.4303 & -5.41 \\
0.0075 & 1.0195 & 0.4698 & 0.4512 & -4.11 \\
0.0100 & 1.0363 & 0.4950 & 0.4896 & -1.11 \\
0.0125 & 1.0596 & 0.5348 & 0.5439 & 1.67 \\
0.0150 & 1.0906 & 0.5935 & 0.6211 & 4.44 \\
\hline
\end{tabular}

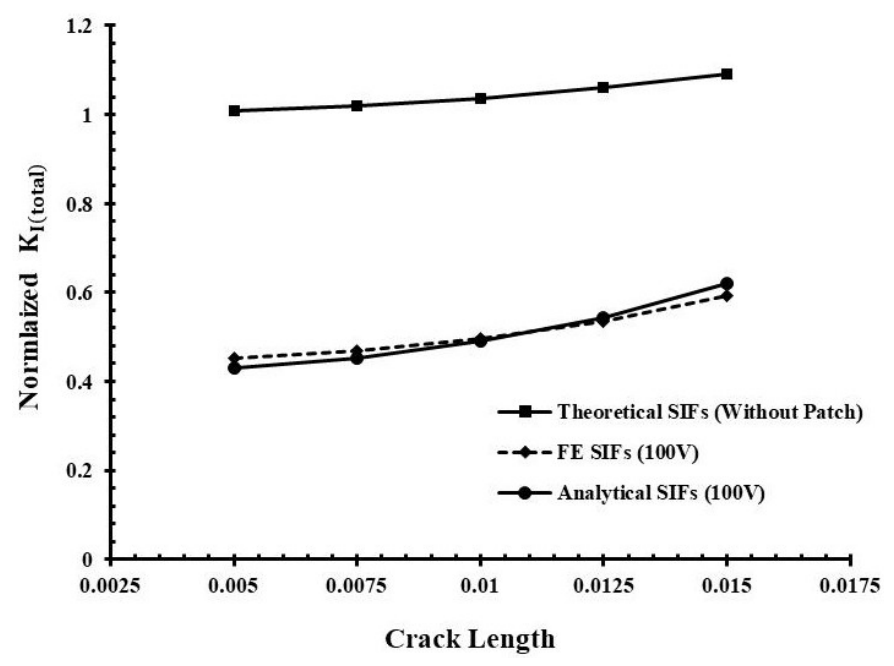

Figure 4. Comparison of the NSIFs between unpatched and patched cracks with application of $100 \mathrm{~V}$.

One notices that increasing the crack length leads to increase of the stress intensity factor. However, applying the piezoelectric actuator with same geometry to different crack lengths also decreases the total stress intensity factor. The reason for such behavior is that the stress produced by the piezoelectric actuator in the host plate is uniform and the results of superimposing this stress to the external stress in the opposite direction leads to linear variation.

The influence of the piezoelectric actuator thickness on the fracture behavior of the repaired plate is shown in Figure 5. Three patch thicknesses were used in order to clarify the thickness effects. By comparing the analytical NSIF proposed modeling in this study with the finite element result, one can see that the agreement is within $\pm 2 \%$. It can be noticed that the decrease of the piezoelectric thickness increased the SIFs reductions.

For a low applied electric field, the relation between the patch thickness and the reduction is moderately large. However, these impacts of increasing the actuator's thickness are not outright, and it has a tendency to be less effective when the electric field applied to the piezoelectric actuators increase.

For a high electric field, this relation turns out to be opposite that of the low electric field (Figure 5d). The conceivable reason for this behavior could be due to the strain produced by the piezoelectric actuator which varies inversely with the actuator thickness. Hence, to accomplish the best result in reduction of the SIFs it is wise to utilize thin actuators with generally high voltage. In fact, these outcomes agree with the work done by Ref. [20,32].

Figure 6 depicts the variation of the induced stresses by the piezoelectric patches into the host plate as a function of the applied voltage for the case of Figure 5a. This blocking stress of the piezoelectric patches, as shown in Figure 2, was calculated using the analytical solution of the stress intensity factor due to the piezoelectric actuators' stresses $\mathrm{K}_{\mathrm{I}(\mathrm{P})}$. 


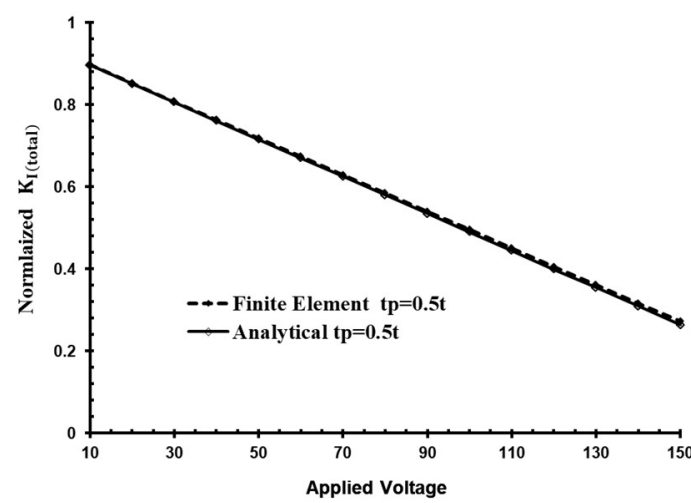

(a)

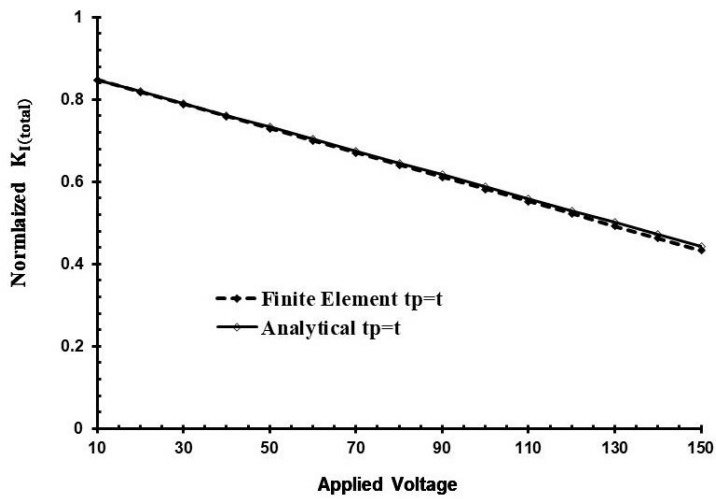

(c)

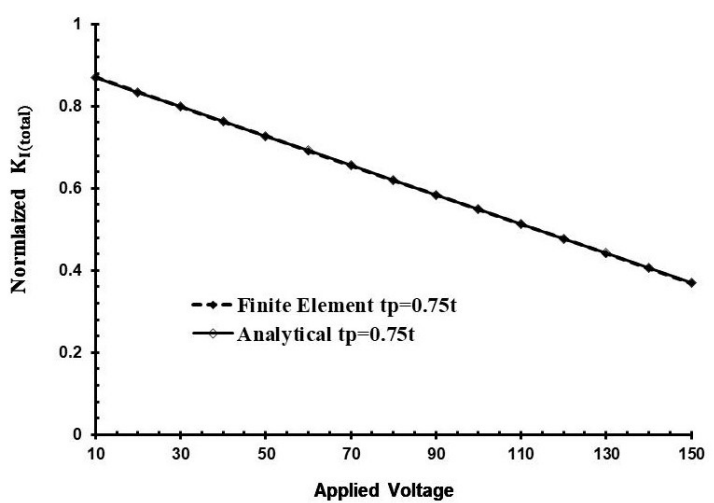

(b)

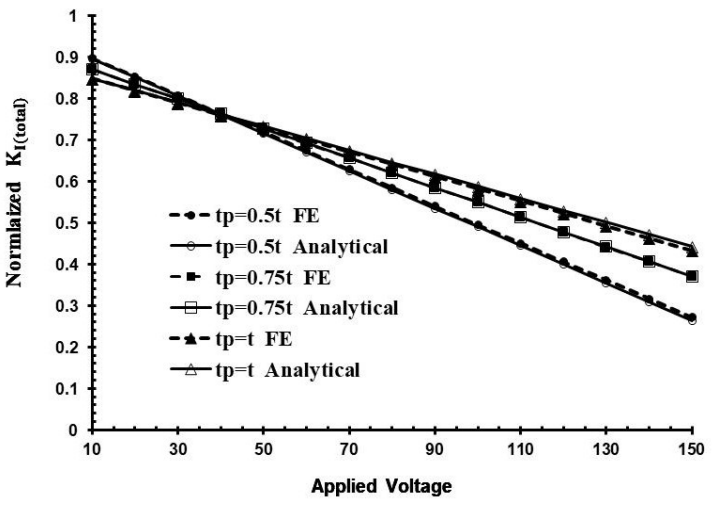

(d)

Figure 5. Variation of analytical and finite element NSIFs with piezoelectric actuator thickness $t_{P}$ (a) $t_{p}=0.5 t,(b) t_{p}=0.75 t,(c) t_{p}=t,(d)$ the three thicknesses plotted together.

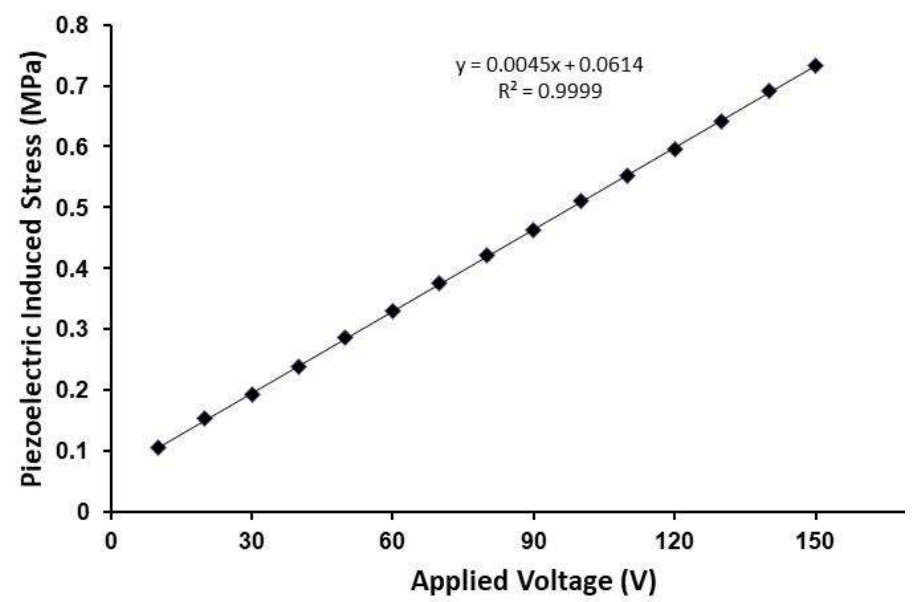

Figure 6. Variation of the induced stresses by the piezoelectric patch as a function of applied voltage.

Furthermore, previous works had proved that the thickness ratio and stiffness ratio of piezoelectric patches and host plate have an effect on the reduction of stress intensity factor. Indeed, Abuzaid et al. [23] showed that to achieve the best result in reduction in the SIF, it is better to use a thin actuator with relatively high voltage. Fesharaki et al. [33] compared the capability of the piezoelectric actuators with different stiffness/thickness ratios in reducing the stress concentration factor in a plate with a hole. By defining stiffness ratio as $E_{\text {plate }} / E_{\text {piezo }}$ and thickness ratio as $t_{\text {plate }} / t_{\text {piezo }}$, they found that at thickness ratios less than 1 , more reduction in the stress concentration factor occurred. Hence, 
to achieve the maximum reduction in the stress concentration factor, the plate thickness should be lower than that of the piezoelectric actuators. In contrast, the stiffness ratios greater than 1 showed some reduction in the stress concentration factor even though the biggest reduction was also observed for stiffness ratios less than 1 .

In the active repair of a cracked structure, the main objective is to decrease the singular stress at the vicinity of the crack tip. However, the capability of the piezoelectric patches to induce stresses on the hosting structures is affected by the stiffness of the latter. For example, if the host structure is steel, the piezoelectric patch would have lower authority than that on an aluminum plate. Accordingly, to achieve higher reduction in the stress intensity factor, the host plate material should be softer than that of the piezoelectric actuator. The increase of the crack length leads to increase of stress intensity factor. For the convenience of observing the impact of different applied voltages on the cracked body SIFs, analytical and finite element results for three different crack lengths are represented in Figure 7. As the crack length is increased, the SIFs also increased and hence a higher electric field is required in order to decrease the SIFs, as shown in Figure 7. The outcomes demonstrate that the reduction of the SIF is linear with the increase of the voltage. Indeed, this is due to the compression stress generated by the piezoelectric actuator which is proportional to the applied voltage.

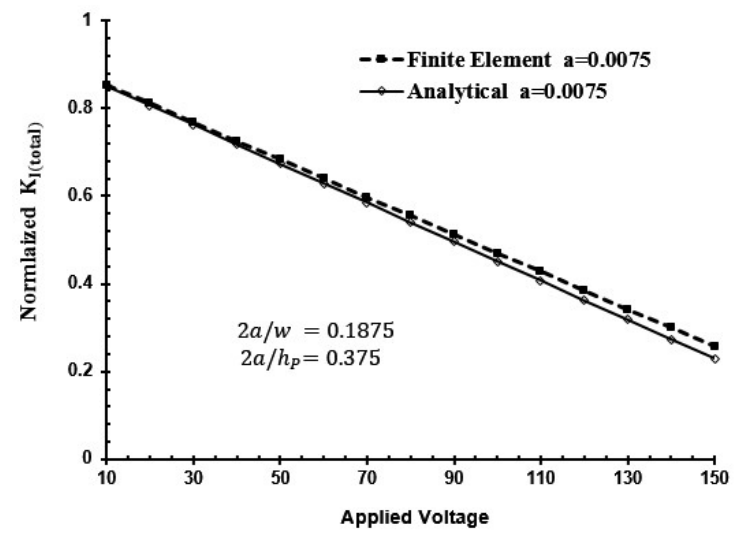

(a)

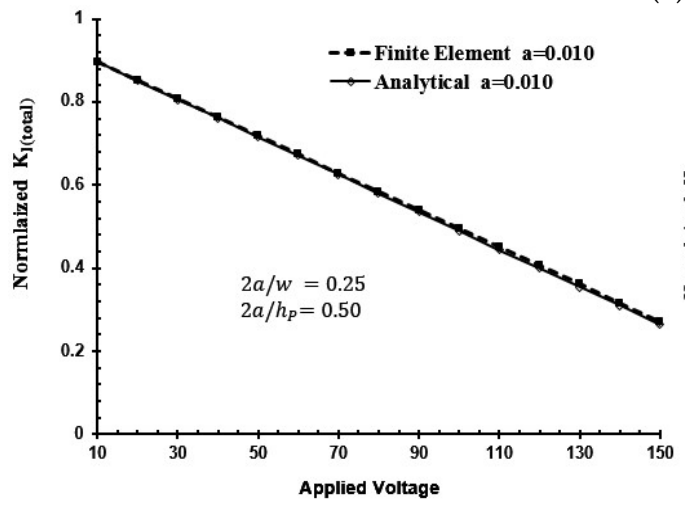

(b)

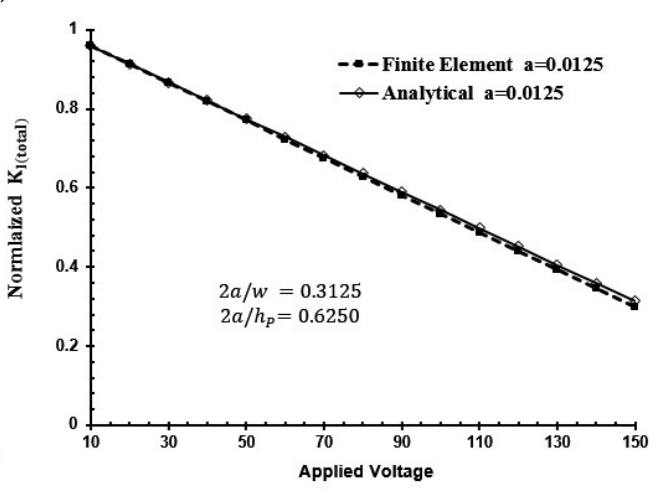

(c)

Figure 7. Variation of the normalized SIF with the crack length (a) crack length $a=0.0075 \mathrm{~m}$, (b) $\mathrm{a}=0.010 \mathrm{~m},(\mathbf{c}) \mathrm{a}=0.0125 \mathrm{~m}$

For the situation when $\left(2 \mathrm{a} / \mathrm{h}_{\mathrm{p}}=0.625\right)$, the decrease of the stress intensity factors is around $71 \%$ compared to $75 \%$ in the case of $\left(2 \mathrm{a} / \mathrm{h}_{\mathrm{p}}=0.375\right)$, with an applied voltage of $150 \mathrm{~V}$. These outcomes indicate that the lower values of $2 \mathrm{a} / \mathrm{h}_{\mathrm{P}}$ are vital to accomplish the objective of the maximum SIF reduction.

The geometry of the piezoelectric patch plays an important role in the variation of the SIF. To highlight the effects of the actuator size in the process of repair of a central crack active repair, three 
different $w_{P} / h_{P}$ ratios were chosen. Figure 8 shows the variations of SIFs with respect to the different geometry of the piezoelectric actuators.

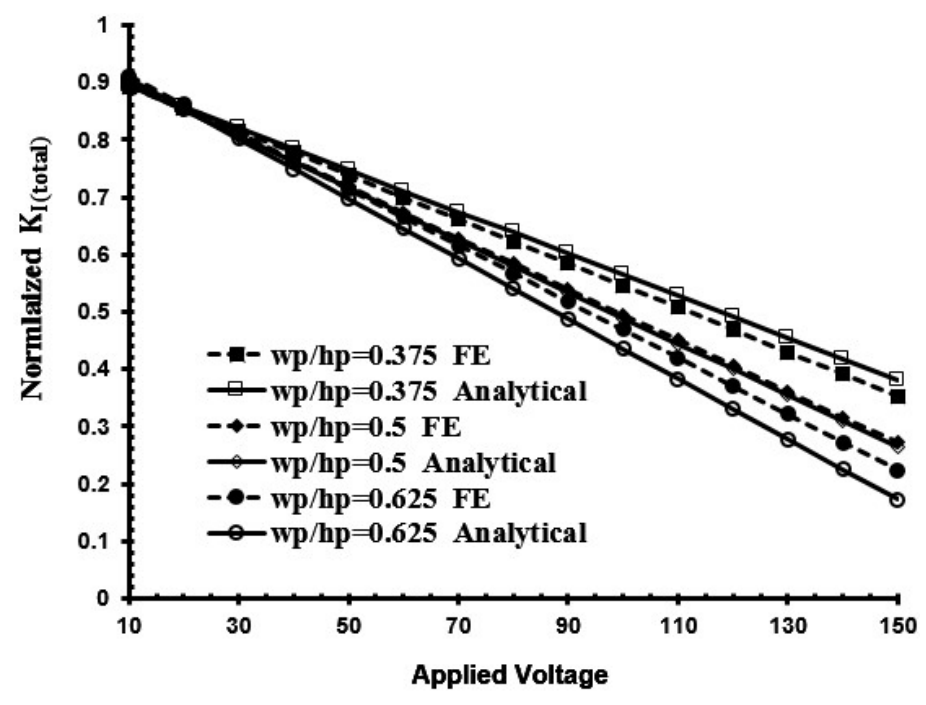

Figure 8. Variation of SIF with piezoelectric actuator size.

The SIF reduction in the model is found to be directly proportional to the actuator patch geometrical area. This is due to the fact that the increase in patch size increases the induced stress which leads to more load transfer through the patch and hence more reduction in SIF is observed in the case of $\mathrm{w}_{\mathrm{P}} / \mathrm{h}_{\mathrm{P}}=0.625$ compared to the other cases. One can see that for the small applied electric field $(\mathrm{v}>30 \mathrm{~V})$, the difference of the normalized SIFs values for cases is very small. Beyond that, the difference takes the extent with the increase of the applied electric field. This confirms that the patch with large value of $\mathrm{w}_{\mathrm{P}}$ produces higher strain on the crack front and provides a better stress redistribution.

For the goal of assessing the active gain of using the piezoelectric actuator for repair, the reductions of the SIF were also monitored, and the outcomes for various patch thicknesses are depicted in Figure 9. It is obvious from the results that the piezoelectric actuator is effective in all terms of SIF reduction. The thin actuator has a tendency to be more viable with the use of the high applied electric filed. However, the thick actuators give better performance with low applied electric field and also increase the passive stiffness of the integrated structure.

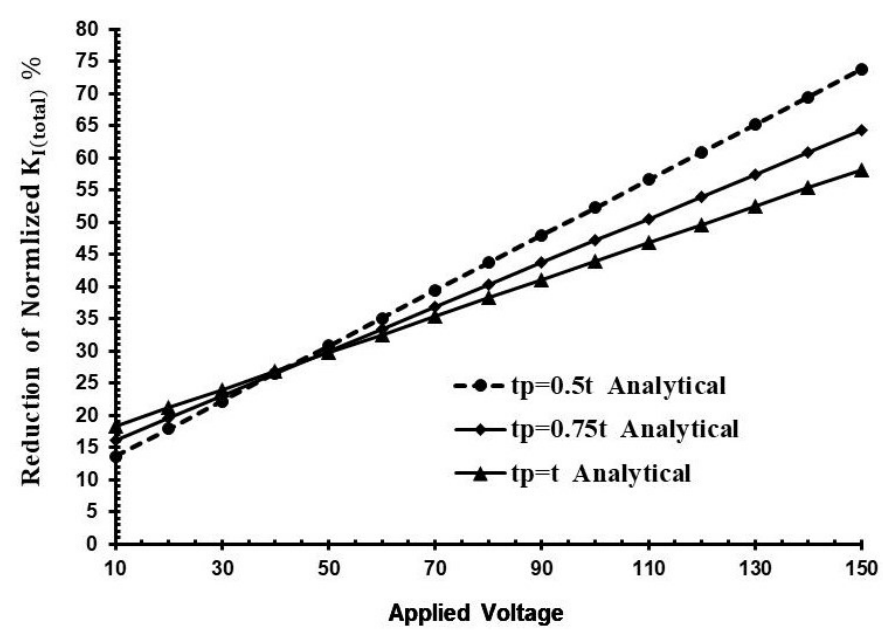

Figure 9. Gain of SIFs with different thickness. 
Generally, the load transferred into the host structure from the piezoelectric actuator determines the effectiveness of the active repair. These loads rely on upon various variables, for example, the size, thickness, material properties, and the electric coupling behavior of the piezoelectric actuator.

Finally, many applications exist where the use of double-sided PZT actuators bonded symmetrically to the upper and lower surface of the host structure cannot be considered. Thus, it is worthwhile to examine the performance characteristics of single-sided actuators configuration in comparison to the double-sided actuators configuration. Intuitively, one might expect double-sided configuration to as much as double the SIF reduction in comparison to a single-sided configuration. Figure 10 shows a comparison between the two configurations. Surprisingly, double-sided configuration achieved less than twice the SIF reduction of single-sided configuration $(138 \%$ for the maximum difference observed at $150 \mathrm{~V}$ ). This result is plausible for the thin aluminum plate tested in this work as the single-sided patches were able to induce smaller stresses on the opposite side of the plate. However, when doubling the host plate thickness to $2 \mathrm{~mm}$, the induced stresses on the opposite side were practically zero. Thus, the application of single-sided actuators to reduce SIF is restricted to very thin aluminum plates.

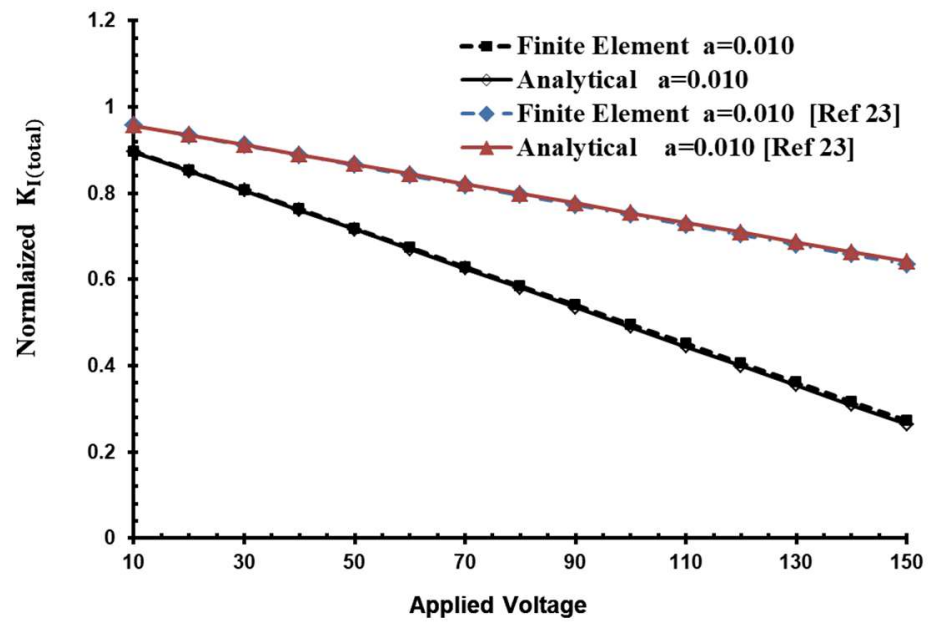

Figure 10. Variation of NSIF with applied voltage for double-sided and single-sided configurations.

\section{Conclusions}

In this study, an analytical model for the active repair of center-cracked plates using piezoelectric actuators was developed. The analytical model has been developed using the weight function approach. In addition, the superposition method was applied for the solution of the stress intensity factor produced by the piezoelectric actuator on the center cracked plate and the solution stress intensity factor due to the tension load. Moreover, the proposed theoretical model was verified by finite element simulation. These solutions are then superimposed to yield the total stress intensity factor for the integrated piezoelectric actuator to the center-cracked plate. The results indicate that the relative errors of the analytical model and the FEA results are less than $5 \%$ in all the cases studied in this paper. The following conclusions were derived from this study:

- For very thin aluminum plates, the application of the stress produced by the piezoelectric actuator at the crack tip decreases the stress intensity factor.

- The piezoelectric actuator's geometry plays an important role in effective repair of the center-cracked plate.

- To achieve the best result in reduction of the SIFs, it is a good idea to use thin actuators with relatively high voltage.

- An accurate result with less than $1.2 \%$ discrepancy can be found when the piezoelectric actuator's width is double the crack length. 
- The reductions of the SIF with an increase in the actuator's thickness are not absolute and tend to be inverse to the application of high voltage.

Author Contributions: Ahmed Abuzaid derived the analytical model, simulated the numerical results and drafted the manuscript. Meftah Hrairi was the main supervisor and adviser of the work and contributed to the analytical model, FEA simulations, analysis of data and writing the manuscript. Mohd Sultan Shaik Dawood was also a supervisor of the work and contributed to the manuscript by reviewing and editing its contents.

Acknowledgments: The authors gratefully acknowledge the support by the Research Management Centre (RMC) at the International Islamic University Malaysia and the Ministry of Higher Education Malaysia under the Fundamental Research Grant Scheme (FRGS15-189-0430).

Conflicts of Interest: The authors declare no conflict of interest.

\section{References}

1. Wang, Q.; Wu, N. A review on structural enhancement and repair using piezoelectric materials and shape memory alloys. Smart Mater. Struct. 2012, 21, 013001. [CrossRef]

2. Abuzaid, A.; Hrairi, M.; Dawood, M.S.I. Survey of Active Structural Control and Repair Using Piezoelectric Patches. Actuators 2015, 4, 77-98. [CrossRef]

3. Wu, N.; Wang, Q. An experimental study on the repair of a notched beam subjected to dynamic loading with piezoelectric patches. Smart Mater. Struct. 2011, 20, 115023. [CrossRef]

4. Wu, N.; Wang, Q. Repair of vibrating delaminated beam structures using piezoelectric patches. Smart Mater. Struct. 2010, 19, 035027. [CrossRef]

5. Wu, N.; Wang, Q. Repair of a delaminated plate under static loading with piezoelectric patches. Smart Mater. Struct. 2010, 19, 105025. [CrossRef]

6. Wang, Q.; Quek, S.T.; Liew, K.M. On the repair of a cracked beam with a piezoelectric patch. Smart Mater. Struct. 2002, 11, 404-410. [CrossRef]

7. Wang, Q.; Quek, S.T. Repair of cracked column under axially compressive load via piezoelectric patch. Comput. Struct. 2005, 83, 1355-1363. [CrossRef]

8. Wang, Q.; Quek, S.T. Repair of delaminated beams via piezoelectric patches. Smart Mater. Struct. 2004, 13, 1222-1229. [CrossRef]

9. Wang, Q.; Duan, W.H.; Quek, S.T. Repair of notched beam under dynamic load using piezoelectric patch. Int. J. Mech. Sci. 2004, 46, 1517-1533. [CrossRef]

10. Ariaei, A.; Ziaei-Rad, S.; Ghayour, M. Repair of a cracked Timoshenko beam subjected to a moving mass using piezoelectric patches. Int. J. Mech. Sci. 2010, 52, 1074-1091. [CrossRef]

11. Alaimo, A.; Milazzo, A.; Orlando, C.; Messineo, A. Numerical analysis of piezoelectric active repair in the presence of frictional contact conditions. Sensors 2013, 13, 4390-4403. [CrossRef] [PubMed]

12. Alaimo, A.; Milazzo, A.; Orlando, C. On the dynamic behavior of piezoelectric active repair by the boundary element method. J. Intell. Mater. Syst. Struct. 2011, 22, 2137-2146. [CrossRef]

13. Platz, R.; Stapp, C.; Hanselka, H. Statistical approach to evaluating reduction of active crack propagation in aluminum panels with piezoelectric actuator patches. Smart Mater. Struct. 2011, 20, 085009. [CrossRef]

14. Liu, T.J.C. Crack repair performance of piezoelectric actuator estimated by slope continuity and fracture mechanics. Eng. Fract. Mech. 2008, 75, 2566-2574. [CrossRef]

15. Toledo, J.; Ruiz-Díez, V.; Diaz-Molina, A.; Ruiz, D.; Donoso, A.; Bellido, J.C.; Wistrela, E.; Kucera, M.; Schmid, U.; Hernando-García, J.; et al. Design and Characterization of In-Plane Piezoelectric Microactuators. Actuators 2017, 6, 19. [CrossRef]

16. Vazquez Carazo, A.; Uchino, K. Novel Piezoelectric-Based Power Supply for Driving Piezoelectric Actuators Designed for Active Vibration Damping Applications. J. Electroceramics 2001, 7, 197-210. [CrossRef]

17. Vazquez Carazo, A. Piezoelectric Transformers: An Historical Review. Actuators 2016, 5, 12. [CrossRef]

18. Miao, S.; Wang, F.; Ma, X. A new transformerless buck-boost converter with positive output voltage. IEEE Trans. Ind. Electron. 2016, 63, 2965-2975. [CrossRef]

19. Xu, Z.; Wang, Y.; Chen, C. Micro converter with a high step-up ratio to drive a piezoelectric bimorph actuator applied in mobile robots. Int. J. Adv. Robot. Syst. 2018, 1-9. [CrossRef]

20. Liu, T.J.C. Fracture mechanics and crack contact analyses of the active repair of multi-layered piezoelectric patches bonded on cracked structures. Theor. Appl. Fract. Mech. 2007, 47, 120-132. [CrossRef] 
21. Abuzaid, A.; Hrairi, M.; Dawood, M.S.I. Mode I stress intensity factor for a cracked plate with an integrated piezoelectric actuator. Adv. Mater. Res. 2015, 1115, 517-522. [CrossRef]

22. Abuzaid, A.; Dawood, M.S.I.; Hrairi, M. Effects of Adhesive Bond on Active Repair of Aluminium Plate Using Piezoelectric Patch. Appl. Mech. Mater. 2015, 799-800, 788-793. [CrossRef]

23. Abuzaid, A.; Hrairi, M.; Dawood, M.S.I. Modeling approach to evaluating reduction in stress intensity factor in center-cracked plate with piezoelectric actuator patches. J. Intell. Mater. Syst. Struct. 2017, 28, 1334-1345. [CrossRef]

24. Fesharaki, J.J.; Golabi, S. Effect of stiffness ratio of piezoelectric patches and plate on stress concentration reduction in a plate with a hole. Mech. Adv. Mater. Struct. 2017, 24, 253-259. [CrossRef]

25. Fesharaki, J.J.; Golabi, S. A novel method to specify pattern recognition of actuators for stress reduction based on Particle swarm optimization method. Smart Struct. Syst. 2016, 17, 725-742. [CrossRef]

26. Maleki, V.A.; Mohammadi, N. Buckling analysis of cracked functionally graded material column with piezoelectric patches. Smart Mater. Struct. 2017, 26, 035031. [CrossRef]

27. Tada, H.; Paris, P.C.; Irwin, G.R. The Stress Analysis of Cracks Handbook, 3rd ed.; ASME Press: New York, NY, USA, 2000, ISBN 0791801535

28. Bueckner, H. Novel principle for the computation of stress intensity factors. Z. Angew. Math. Mech. 1970, 50, 529-546.

29. Fett, T.; Munz, D. Stress Intensity Factors and Weight Functions; Computational Mechanics Publications: Southampton, UK, 1997, ISBN 1853124974.

30. Rice, J.R. Some remarks on elastic crack-tip stress fields. Int. J. Solids Struct. 1972, 8, 751-758. [CrossRef]

31. Anderson, T.L.; Anderson, T. Fracture Mechanics: Fundamentals and Applications, 3rd ed.; CRC Press: Boca Raton, FL, USA, 2005, ISBN 9781420058215.

32. Crawley, E.F.; De Luis, J. Use of piezoelectric actuators as elements of intelligent structures. AIAA J. 1987, 25, 1373-1385. [CrossRef]

33. Fesharaki, J.J.; Madani, S.G.; Golabi, S. Effect of stiffness and thickness ratio of host plate and piezoelectric patches on reduction of the stress concentration factor. Int. J. Adv. Struct. Eng. 2016, 8, 229-242. [CrossRef]

(C) 2018 by the authors. Licensee MDPI, Basel, Switzerland. This article is an open access article distributed under the terms and conditions of the Creative Commons Attribution (CC BY) license (http://creativecommons.org/licenses/by/4.0/). 